\title{
Comparison of Optimized 3D-SPACE and 3D-TSE Sequences at 1.5T MRCP in the Diagnosis of Choledocholithiasis
}

\section{MRCP mit optimierter 3D-SPACE-Sequenz: Ein Vergleich mit der konventionellen 3D-TSE-Sequenz bei der Diagnostik der Choledocholithiasis}

Authors

Affiliations
P. Sudholt ${ }^{1}$, C. Zaehringer ${ }^{2}$, C. Urigo ${ }^{3}$, A. Tyndall ${ }^{2}$, G. Bongartz ${ }^{2}$, J. Hohmann ${ }^{2}$

Department of Diagnostic and Interventional Radiology, University Hospital Marburg, Germany

Clinic for Radiology and Nuclear Medicine, University Hospital Basel, Switzerland

3 Radiology, Ars Medica Clinic, Gravesano-Lugano, Switzerland

\author{
Key words \\ - abdomen \\ - biliary system \\ - gallbladder, calculi \\ - MR imaging
}

received 17.6.2014

accepted 15.1.2015

Bibliography

DOI http://dx.doi.org/

10.1055/s-0034-1399271

Published online: 15.4.2015

Fortschr Röntgenstr 2015; 187 :

467-471 @ Georg Thieme

Verlag KG Stuttgart · New York .

ISSN 1438-9029

\section{Correspondence}

Philipp Sudholt

Diagnostische und

Interventionelle Radiologie,

Universitätsklinikum Marburg

Baldingerstraße

35043 Marburg

Tel.: ++49/6421/5860

Fax: ++49/6421/5868959

sudholt@gmail.com

\section{Zusammenfassung}

$\nabla$

Ziel: Die vorliegende Studie soll zeigen, dass eine MRCP im Rahmen der klinischen Routinediagnostik einer Cholezystolithiasis und/oder einer Choledocholithiasis unter Verwendung einer 3D-SPACESequenz eine bessere Bildqualität und eine höhere diagnostische Konfidenz besitzt als die bislang normalerweise angewendete 3D-TSE-Sequenz.

Material und Methoden: Eine 3D-SPACE- und 3DTSE-Sequenz wurde bei 42 Patienten durchgeführt, die sich einer MRCP mit Verdacht auf Choledocholithiasis unterzogen. Die Beurteilung der Bildqualität und der diagnostischen Konfidenz der Cholangien und des Ductus pancreaticus erfolgte getrennt nach insgesamt 10 Segmenten der Gangsysteme bezüglich des Vorhandenseins von Konkrementen. Drei Radiologen mit unterschiedlicher Erfahrung in abdomineller Radiologie bewerteten diese Parameter auf einer fünfstelligen Skala von 1 bis 5 respektive -2 bis +2 . Die statistische Auswertung erfolgte mittels Studentt-Test. Zusätzlich wurde auch das InterobserverAgreement mittels Cohen- $\mathrm{k}$-Statistik berechnet.

Ergebnisse: Die Bildqualität der 3D-SPACE-Sequenz wurde von den befundenden Radiologen signifikant besser als bei der 3D-TSE-Sequenz bewertet $(4,48 \pm 0,94$ vs. $3,98 \pm 1,20$; 5 -Punkte-Skala; $\mathrm{p}<0,01$ ). Auch die diagnostische Konfidenz war bei der 3D-SPACE signifikant besser $(1,68 \pm$ 0,56 vs. $1,46 \pm 0,70$; 3 -Punkte-Skala; $\mathrm{p}<0,01$ ). Dies traf für jedes der untersuchten Segmente der Gallenwege zu, besonders deutlich in der klinisch wichtigen periampullären Region. Das Interobserver-Agreement war für beide Sequenzen mit 0,62-0,83 bzw. 0,64-0,82 hoch.

Schlussfolgerung: Die optimierte 3D-SPACE-Sequenz liefert in der klinischen Routine auch bei 1,5 T eine bessere Bildqualität und eine höhere diagnostische Konfidenz im Vergleich zur konventionellen 3D-TSE-Sequenz und sollte entsprechend als Standard eingesetzt werden.

\section{Abstract \\ $\nabla$}

Purpose: The aim of the study was to evaluate whether or not MRCP using a 3D-SPACE sequence allows for better image quality and a higher level of diagnostic confidence than a conventional 3D-TSE sequence at $1.5 \mathrm{~T}$ regarding the diagnosis of choledocholithiasis in a routine clinical setting. Materials and Methods: 3D-SPACE and 3D-TSE sequences were performed in 42 consecutive patients with suspected choledocholithiasis undergoing MRCP. Evaluation of image quality and diagnostic confidence was done on the pancreaticobiliary tree which was subdivided into 10 segments. They were scored and statistically evaluated separately for visibility and diagnostic certainty by three radiologists with differing levels of experience on a five-point scale of 1 to 5 and -2 to 2 , respectively. Student t-test was performed, and the interobserver agreement was also calculated.

Results: Image quality for each segment was significantly better for the 3D-SPACE sequence compared to the 3D-TSE sequence ( $4.48 \pm 0.94$ vs. $3.98 \pm$ 1.20 ; 5 -point scale $\mathrm{p}<0.01$ ). Diagnostic confidence for the reporting radiologist was also significantly better for 3D-SPACE than for 3D-TSE $(1.68 \pm 0.56$ vs. $1.46 \pm 0.70 ; 3$-point scale; $\mathrm{p}<0.01$ ). The interobserver agreement was high in both sequences, $0.62-0.83$ and $0.64-0.82$, respectively.

Conclusion: The optimized 3D-SPACE sequence allows for better image quality in $1.5 \mathrm{~T}$ MRCP examinations and leads to a higher diagnostic confidence for choledocholithiasis compared to the conventional 3D-TSE sequence.

Key Points:

- 3D-SPACE allows for better image quality in 1.5 T MRCP.

- This leads to a higher diagnostic confidence particularly in the periampullary region.

- 3D-SPACE should be considered to substitute conventional 3D-TSE sequences in clinical routine MRCP. 
Kernaussagen:

- Die 3D-SPACE-Sequenz bietet im Rahmen der 1,5T-MRCP eine überlegene Bildqualität aufgrund höherer Konturschärfe.

- Dies führt zu einer höheren diagnostischen Sicherheit insbesondere in der wichtigen Papillenregion.

- In der klinischen Routine sollte die 3D-SPACE die konventionelle 3D-TSE-Sequenz ersetzen.
Citation Format:

- Sudholt P, Zaehringer C, Urigo C et al. Comparison of Optimized 3D-SPACE and 3D-TSE Sequences at 1.5T MRCP in the Diagnosis of Choledocholithiasis. Fortschr Röntgenstr 2015; 187: 467-471

\section{Introduction}

$\nabla$

Magnetic resonance cholangiopancreatography (MRCP) is a standard imaging technique that provides detailed information of the pancreaticobiliary anatomy and pathology [1]. Heavily T2-weighted (T2w) sequences with long echo times (TE) clearly depict fluid-filled compartments [2,3]. A variety of magnetic resonance (MR) sequences for MRCP have been introduced at $1.5 \mathrm{Te}$ sla (T) which differ for various imaging properties. Most protocols have used two-dimensional single-shot fast spin-echo (2D-SSFSE) sequences [4] in which respiratory motion artifacts were a major problem. Breath-hold techniques have been applied to eliminate this limitation.

Today, a 3-dimensional navigator-triggered technique using turbo spin-echo (3D-TSE) sequences is widely used to obtain high resolution 3D-MRCP images [5]. Recently it has been attempted to use a 3-dimensional sampling perfection with application-optimized contrasts using a different flip angle evolution (3DSPACE) sequence at $3 \mathrm{~T}$ to eliminate ghosting artifacts while maintaining image quality and sufficient contrast-to-noise ratio (CNR) $[6,7]$. In healthy volunteers it has been shown that 3DSPACE allows for high-quality imaging of the biliary tract and has the ability to depict non-dilated and dilated intrahepatic ducts very clearly [7]. However, 3D-SPACE can also be used at $1.5 \mathrm{~T}$ [8]. The contour sharpness of 3D-SPACE MRCP is quantitatively and qualitatively superior to that of conventional 3D-TSE MRCP [5]. It also revealed a higher conspicuity of stones together with a shorter acquisition time while using almost identical sequence parameters [9].

The aim of this study was to evaluate the image quality and the level of diagnostic confidence for choledocholithiasis of optimized 3D-SPACE and 3D-TSE sequences in a routine clinical setting.

\section{Materials and Methods \\ $\nabla$}

The study had Institutional Review Board (IRB) approval. Due to the retrospective nature of the study, written informant consent was waived.

\section{Subject Population}

We included 42 patients (18 female, 24 male; mean age $65 \pm 16$ years; age range 31 - 96 years) with suspected choledocholithiasis referred for MRCP during a time period of five months. Regarding patient history, the clinical data on the radiology order form was evaluated. The only inclusion criterion was a high clinical suspicion for choledocholithiasis. Patients with other pancreatobiliary diseases such as malignomas were excluded.

\section{MRCP Imaging Technique}

All MRCP examinations were performed on a commercially available $1.5 \mathrm{~T}$ imaging system (Magnetom Avanto, Siemens Medical
Solutions, Erlangen, Germany) with a phased-array body coil. We used our standard MRCP protocol (3D-TSE, T2w Half-Fourier acquisition single-shot turbo spin-echo (HASTE) thick $(80 \mathrm{~mm})$ and thin ( $5 \mathrm{~mm}$ slices coronal), T2w TRUFI axial and coronal) together with the 3D-SPACE sequence. We obtained the navigatortriggered 3D-SPACE and 3D-TSE images of the pancreaticobiliary tree during free breathing in all subjects. For respiratory triggering, we used the prospective acquisition correction (PACE) technique. We did not use parallel imaging for both sequences to avoid additional artifacts. The sequences were implemented and optimized to the MRI scanner being used. Optimization was done mainly with respect to a high spatial resolution while maintaining an almost identical acquisition time for both sequences. As expected, echo spacing, which is critical for contour sharpness, was $60 \%$ higher in conventional 3D-TSE than in the optimized 3D-SPACE sequence (values calculated by the Siemens scanner software). A pre-series evaluation was performed with 5 patients ( 3 female, 2 male; mean age: 58.4 years, range: 30 - 87 years). The resulting sequence parameters are shown in $\bullet$ Table 1.

\section{Qualitative Analysis}

Three radiologists (PS, CU, JH) with two, three and eight years of experience in abdominal radiology assessed the images independently. They evaluated the image quality of predefined segments of the pancreaticobiliary tree using a 5-point scale: 1 =not displayed; 2 =incompletely displayed, not diagnostic; $3=$ all parts of the segments are uncertainly definable, still diagnostic; 4 = all parts of the segments are included, some are uncertainly definable, still diagnostic; 5 = all parts of the segments are completely and reliably definable. The intrahepatic, extrahepatic,

Table 1 Sequence parameters for 3D-SPACE and 3D-TSE that were used in our study.

Tab. 1 Sequenzparameter für 3D-SPACE- und 3D-TSE-Sequenzen.

\begin{tabular}{|c|c|c|}
\hline & 3D-SPACE & 3D-TSE \\
\hline TR & $1800 \mathrm{~ms}$ & $1800 \mathrm{~ms}$ \\
\hline TE & $700 \mathrm{~ms}$ & $650 \mathrm{~ms}$ \\
\hline effective TE & $669 \mathrm{~ms}$ & $678 \mathrm{~ms}$ \\
\hline flip angle & $130^{\circ}$ & $150^{\circ}$ \\
\hline matrix & $320 \times 311$ & $230 \times 256$ \\
\hline field of view & $320 \times 320$ & $256 \times 232$ \\
\hline section thickness & $1.2 \mathrm{~mm}$ & $1.5 \mathrm{~mm}$ \\
\hline voxel size & $1.25 \mathrm{~mm}^{3}$ & $1.5 \mathrm{~mm}^{3}$ \\
\hline echo spacing & $5 \mathrm{~ms}$ & $8 \mathrm{~ms}$ \\
\hline echo train length & 161 & 127 \\
\hline acquisition plane & coronal & coronal \\
\hline respiratory triggering & PACE & PACE \\
\hline acquisitiontime (pre-series) & $6: 49 \pm 1: 15 \mathrm{~min}$ & $7: 49 \pm 1: 15$ \\
\hline
\end{tabular}

Optimization was done mainly with respect to a high spatial resolution while maintaining a comparable acquisition time for both sequences.

Optimiert wurden die Sequenzen primär in Hinblick auf eine hohe räumliche Auflösung; die Untersuchungszeit war für beide Sequenzen vergleichbar. 


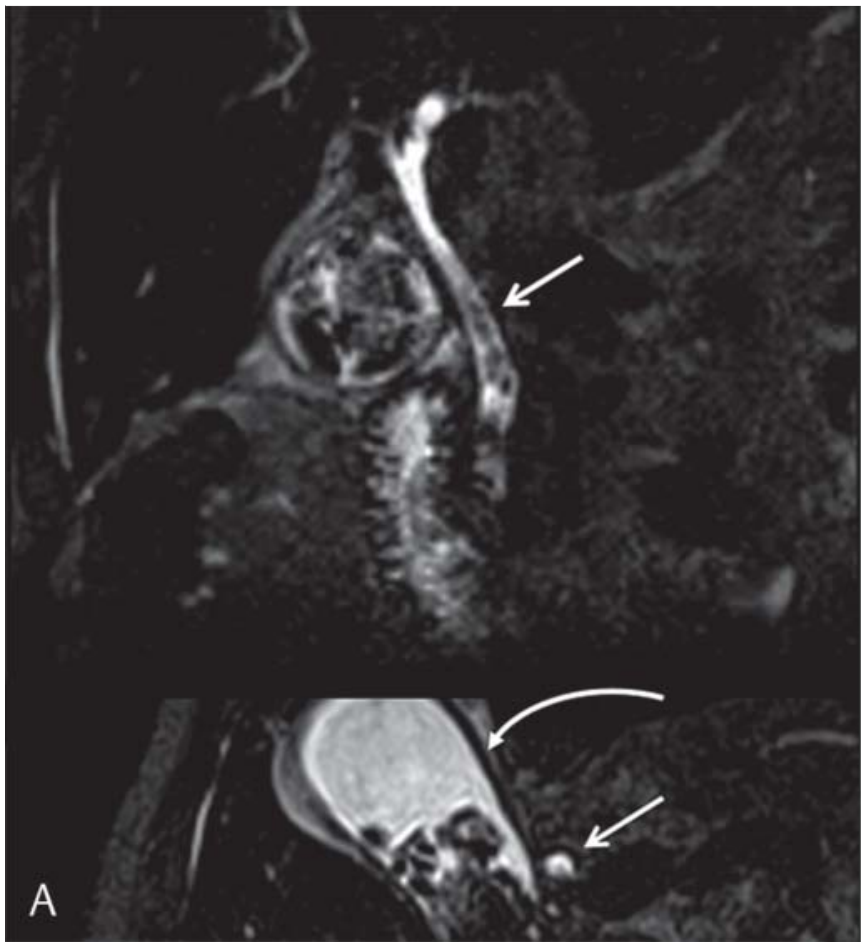

Fig. 1 Image sample 3D-SPACE MRCP vs. 3D-TSE MRCP. Comparison of 3D-SPACE MRCP A vs. 3D-TSE MRCP B in a patient with choledocholithiasis and cholecystolithiasis (coronal and axial reformation). The higher contour sharpness of the 3D-SPACE sequence allows for better delineation of the concrements and for identification of additional concrements (straight arrow). The wall structures show less blurring in 3D-SPACE (curved arrow).

cystic bile duct and the pancreatic duct were assessed by dividing them into ten segments: intrahepatic bile ducts (IBD), right hepatic bile duct (RHD), left hepatic bile duct (LHD), common hepatic bile duct (CHD), cystic duct (CD), proximal common bile duct (CBD), distal common bile duct / papilla of Vater (PV), proximal pancreatic duct within the pancreatic head (PPD), distal pancreatic duct (tail and body, DPD) and the gallbladder (GB, $\bullet$ Fig. 2, top). Standard anatomic definitions of duct segments were used. In a second step, the diagnostic confidence was rated on a 5-point scale from -2 to 2 : -2 = reliably no concrement; $-1=$ most likely no concrement; $0=$ not evaluable; 1 =most likely concrement; $2=$ reliably recognized concrement. For the statistical analysis the modulus of this scale was used. During the reading process, the readers were allowed to use multiplanar reformations to evaluate the $3 \mathrm{D}$ datasets.

\section{Statistical Analysis}

Statistical evaluation was performed using Prism 4.01 (GraphPad Software, Inc., La Jolla, CA, USA) and Excel 14.0 (Microsoft, Redmond, USA). Qualitative analysis used a paired student t-test to compare the image quality and the diagnostic confidence of the two sequences.

Interobserver agreement was assessed by calculating the Cohen $\mathrm{k}$ statistic $(\mathrm{k}<0.00$ : poor agreement, $\mathrm{k}=0.00-0.20$ : slight agreement, $\mathrm{k}=0.21-0.40$ : fair agreement, $\mathrm{k}=0.41-0.60$ : moderate agreement, $\mathrm{K}=0.61-0.80$ : substantial agreement; $\mathrm{K}=0.81-1.00$ almost complete agreement).

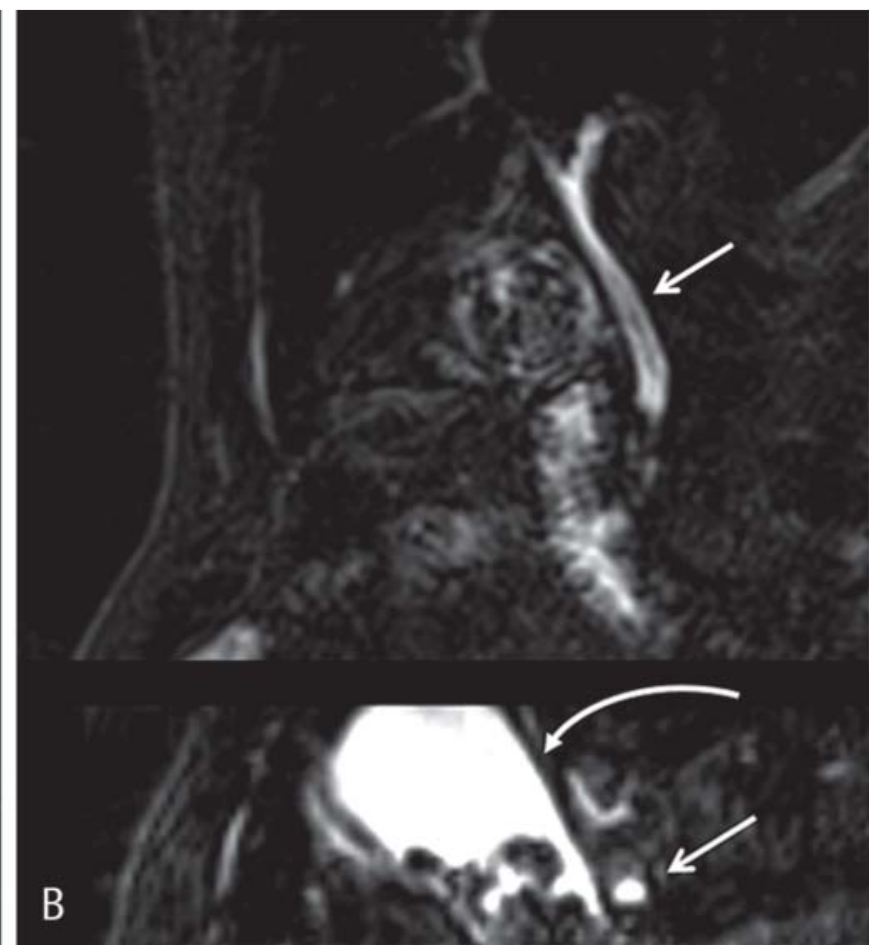

Abb. 1 Bildbeispiele: 3D-SPACE-MRCP versus 3D-TSE-MRCP. Vergleich der 3D-SPACE-MRCP A mit der 3D-TSE-MRCP B bei einem Patienten mit Choledocholithiasis und Cholecystolithiasis (koronare und axiale Reformatierung). Verdeutlicht ist die überlegene Konturdarstellung der 3D-SPACESequenz, die eine bessere Erkennung der Konkremente und die Identifikation zusätzlicher Konkremente ermöglicht. Die Wanddarstellung ist insgesamt schärfer (gekrümmter Pfeil).

\section{Results}

The pre-series evaluation showed no significant differences in the acquisition time (3D-SPACE: 6:49 $\pm 1: 15 \mathrm{~min}$; 3D-TSE: 7:49 \pm $1: 15$ min; $p=0.214$ ). In 35 of 42 patients ( $83 \%$ ), a concrement could be identified by MRCP. Typical Images for both Sequences are shown in $\bullet$ Fig. 1 The results of the image quality analysis are shown in Table 2: 3D-SPACE MRCP showed superior image quality in all segments (average score: 3D-SPACE $4.48 \pm 0.94$ vs. $3 D-T S E 3.98 \pm 1.20, p<0.01$ ). Primarily because of the better delineation of small structures by reduced blurring, 3D-SPACE allowed better evaluation of the segments in a relevant number of patients. The image quality of the common hepatic duct was better evaluated than the other parts of the pancreaticobiliary tree in both sequences (3D-SPACE: $4.81 \pm 0.40$ vs. 3D-TSE: $4.53 \pm 0.73$ vs). The proximal parts of the intrahepatic bile ducts were better distinguishable than the distal parts in both 3D-SPACE and 3DTSE. The image quality of the gallbladder and the cystic duct was evaluated with a lesser score than that of the intrahepatic bile ducts. The distal and proximal pancreatic duct revealed the poorest image quality. The reader with eight years of experience in abdominal radiology valued image quality in both sequences better than the other two readers. However, the interobserver agreement for image quality was substantial to almost complete for the 3D-SPACE $(\mathrm{k}=0.73-0.83)$ and moderate to substantial for the 3D-TSE $(k=0.53-0.79)$ sequence.

The results of the diagnostic confidence are shown in 0 Table 3. Comparison of the diagnostic confidence in both sequences revealed statistically significant results in favor of 3D-SPACE rather 


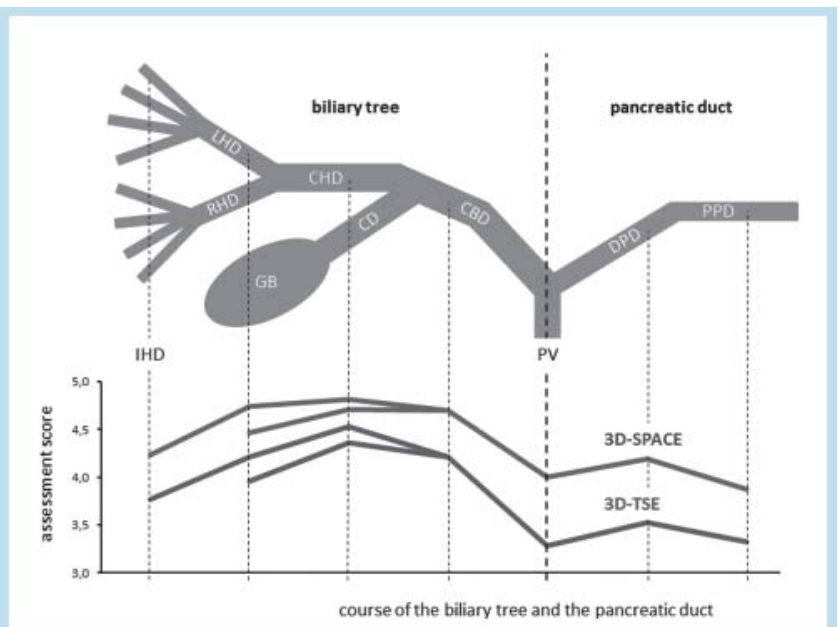

Fig. 2 Segment visibility of the pancreaticobiliary tree. Top: Biliary anatomy was analyzed in 10 predefined segments of the pancreaticobiliary tree: intrahepatic branches; left hepatic duct (LHD), right hepatic duct (RHD), common hepatic duct (CHD), gallbladder, cystic duct, common bile duct (CBD), distal pancreatic duct (distal PD) and proximal pancreatic duct (proximal PD). Bottom: Average segment visibility (1: poor; 5: excellent) by course of the pancreaticobiliary tree (abscissa). 3D-SPACE (blue line) shows superior visibility to 3D-TSE (red line) in all segments. The advantage is most evident in small structures such as the hepatic ducts and in the clinically important periampullary region, which is usually the most difficult region to evaluate in MRCP studies.

Abb. 2 Abgrenzbarkeit der Segmente des pankreatikobiliären Gangsystems. Oben: Aufteilung der Segmente: intrahepatische Äste (IHD), linker und rechter Ductus hepaticus (RHD und LHD), Ductus hepaticus communis (CHD), Gallenblase (GB), Ductus cystikus (DC), Ductus choledochus (CBD), Papilla vateri (PV), distaler Ductus pancreaticus (DPD), proximaler Ductus pancreaticus (PPD); Unten: Qualität der Abgrenzbarkeit der einzelnen Segmente (Ordinate, 1, schlecht; 5, sehr gut) mit 3D-SPACE-MRCP (blaue Linie) gegenüber der 3D-TSE-MRCP (rote Linie) entlang des pankreaticobiliären Gangsystems. Die 3D-SPACE erlaubt eine bessere Darstellung aller Segmente. Am höchsten ausgeprägt ist der Vorteil bei kleinen Strukturen wie den intrahepatischen Gallengängen sowie in der klinisch wichtigen periampullären Region um die Papilla vateri (CBD, PV, DPD), die bei MRCPUntersuchungen häufig schwer zu beurteilen ist.

than 3D-TSE $(1.68 \pm 0.56$ vs. $1.46 \pm 0.70$ vs; three-point scale described above, $\mathrm{p}<0.01)$. Corresponding to the image quality, the diagnostic confidence for the diagnosis of choledocholithiasis in the common hepatic duct was highest. The diagnostic confidence in the gallbladder and in the cystic duct was evaluated to be superior compared with the intrahepatic bile ducts. The proximal intrahepatic bile ducts were assessed with more certainty than the distal intrahepatic bile ducts. The poorest diagnostic confidence was seen in the distal and proximal pancreatic duct and the papilla of Vater. Like for the image quality, the diagnostic confidence was superior for the reader with eight years of experience in abdominal radiology. Interobserver agreement for the diagnostic confidence was substantial to almost complete in both sequences (3D-SPACE: $\mathrm{K}=0.62-0.83$; 3D-TSE: $\mathrm{K}=0.64-0.82$ ).

\section{Discussion}

Our study shows advantages of the 3D-SPACE in comparison with the conventional 3D-TSE for each analyzed segment of the pancreaticobiliary tree. It is known from the literature that 3D-
Table 2 Qualitative analysis of 3D-TSE MRCP and 3D-SPACE-MRCP.

Tab. 2 Qualitative Analyse der Sequenzen.

\begin{tabular}{|c|c|c|c|c|c|}
\hline \multirow[t]{2}{*}{ segment } & \multicolumn{2}{|l|}{ 3D-TSE } & \multicolumn{3}{|l|}{ 3D- SPACE } \\
\hline & mean \pm SD & kappa & mean $\pm S D$ & kappa & p-value \\
\hline gallbladder & $3.96 \pm 1.13$ & 0.65 & $4.47 \pm 0.98$ & 0.80 & $<0.01$ \\
\hline cystic duct & $4.36 \pm 0.99$ & 0.77 & $4.71 \pm 0.75$ & 0.83 & $<0.01$ \\
\hline $\begin{array}{l}\text { distal common } \\
\text { bile duct }\end{array}$ & $3.28 \pm 1.43$ & 0.71 & $4.00 \pm 1.17$ & 0.75 & $<0.01$ \\
\hline $\begin{array}{l}\text { proximal common } \\
\text { bile duct }\end{array}$ & $4.21 \pm 1.05$ & 0.72 & $4.70 \pm 0.69$ & 0.83 & $<0.01$ \\
\hline $\begin{array}{l}\text { common hepatic } \\
\text { duct }\end{array}$ & $4.53 \pm 0.73$ & 0.79 & $4.81 \pm 0.40$ & 0.83 & $<0.01$ \\
\hline right hepatic duct & $4.33 \pm 0.82$ & 0.78 & $4.75 \pm 0.55$ & 0.82 & $<0.01$ \\
\hline left hepatic duct & $4.12 \pm 1.10$ & 0.79 & $4.72 \pm 0.59$ & 0.82 & $<0.01$ \\
\hline intrahepatic ducts & $3.77 \pm 1.07$ & 0.78 & $4.23 \pm 0.95$ & 0.80 & $<0.01$ \\
\hline $\begin{array}{l}\text { proximal pancreatic } \\
\text { duct }\end{array}$ & $3.53 \pm 1.32$ & 0.63 & $4.19 \pm 1.04$ & 0.80 & $<0.01$ \\
\hline distal pancreatic duct & $3.33 \pm 1.38$ & 0.53 & $3.87 \pm 1.28$ & 0.73 & $<0.01$ \\
\hline verage & $3.98 \pm 1.20$ & & $4.48 \pm 0.94$ & & \\
\hline
\end{tabular}

Segment visibility of 3D-TSE-MRCP versus 3D-SPACE-MRCP as average rating of all three readers and interobserver agreement for three readers (kappa). Visibility was measured for 10 segments of the pancreatobiliary tree (right column). A five-point scale was used ( 1 = not displayed; 2 = incompletely displayed, not diagnostic; 3 = all parts of the segments are uncertainly definable, still diagnostic; $4=$ all parts of the segments are uncertainly definable, still diagnostic; 5 = all parts of the segments are completely and securely definable). Corresponding p-values for the average segment rating for 3D-SPACE MRCP vs. 3D-TSE MRCP are given.

Abgrenzbarkeit der Segmente in der 3D-SPACE-MRCP gegenüber der 3D-TSE-MRCP im Mittelwert aller drei Untersucher. Die Bewertung wurde für 10 Segmente des Gallenwegsystems getrennt durchgeführt (rechte Spalte). Bewertet wurde auf einer fünfstelligen Skala (1 = nicht dargestellt; 2 = unvollständig dargestellt, ohne diagnostische Aussagekraft; 3 =nicht mit Sicherheit abgrenzbar, dennoch mit diagnostischer Aussagekraft; 4 = sämtliche Teile des Segments sind abgrenzbar; manche sind nicht sicher abgrenzbar, dennoch mit diagnostischer Aussagekraft; 5 = sämtliche Teile der Segmente sind vollständig und sicher abgrenzbar). Die Interobserver-Reliabiltät ( $\mathrm{k}$-Werte) der drei Untersucher ist angegeben, sowie entsprechende $\mathrm{p}$-Werte der durchschnittlichen Bewertung der 3D-SPACE-MRCP gegenüber der 3D-TSE-MRCP.

MRCP-sequences allow imaging of the biliary tree and pancreatic duct with very good results [3]. In this study, we confirmed these findings, as image quality for both $3 \mathrm{D}$ sequences was assessed as good or very good by the readers (average score $4.48 \pm 0.94$ for 3D-SPACE vs. $3.98 \pm 1.20$ for $3 \mathrm{D}$-TSE on a five-point scale). All readers rated the image quality of 3D-SPACE at 1.5T-MRI as significantly better than the image quality of 3D-TSE. This confirms results previously reported for 3T-MRI by others, where the readers preferred the appearance of images obtained with the SPACE sequence in 3T-MRI [6]. More importantly, our study shows that the better image quality allows a higher level of diagnostic confidence regarding the diagnosis of choledocholithiasis. 3D-SPACE is a more stable sequence than 3D-TSE and leads to higher contour sharpness. Morita et al. showed this in an earlier study with healthy volunteers, in which they achieved better contour sharpness by lowering the echo spacing time [8]. Nakaura et al. used 3DSPACE and 3D-TSE sequences with identical parameters and using parallel imaging in patients [9]. They again found better image quality with 3D-SPACE, but not for all parts of hepatobiliary tree and especially not for the overall assessment. The quantitative analysis revealed a significantly shorter acquisition time and better contrast but not a better CNR. Our study differs in that it used a slightly higher spatial resolution for optimized 3D-SPACE, instead of focalizing on a faster acquisition time. With this improvement, we could achieve significantly better results for the 
Table 3 Diagnostic confidence for choledocholithiasis with 3D-TSE MRCP and 3D-SPACE MRCP.

Tab. 3 Diagnostische Sicherheit, gegliedert nach Segmenten (rechte Spalte), in der 3D-SPACE-MRCP gegenüber der 3D-TSE-MRCP.

\begin{tabular}{|c|c|c|c|c|c|}
\hline \multirow[t]{2}{*}{ segment } & \multicolumn{2}{|l|}{ 3D-TSE } & \multicolumn{3}{|l|}{ 3D-SPACE } \\
\hline & mean \pm SD & kappa & mean $\pm S D$ & kappa & p-value \\
\hline gallbladder & $1.62 \pm 0.63$ & 0.65 & $1.80 \pm 0.45$ & 0.71 & $<0.01$ \\
\hline cystic duct & $1.61 \pm 0.62$ & 0.76 & $1.78 \pm 0.48$ & 0.76 & $<0.01$ \\
\hline $\begin{array}{l}\text { distal common } \\
\text { bile duct }\end{array}$ & $1.10 \pm 0.83$ & 0.65 & $1.45 \pm 0.72$ & 0.62 & $<0.01$ \\
\hline $\begin{array}{l}\text { proximal com- } \\
\text { mon bile duct }\end{array}$ & $1.52 \pm 0.67$ & 0.64 & $1.71 \pm 0.53$ & 0.68 & $<0.01$ \\
\hline $\begin{array}{l}\text { common hepatic } \\
\text { duct }\end{array}$ & $1.69 \pm 0.51$ & 0.82 & $1.81 \pm 0.38$ & 0.80 & $<0.01$ \\
\hline right hepatic duct & $1.57 \pm 0.58$ & 0.79 & $1.78 \pm 0.44$ & 0.83 & $<0.01$ \\
\hline left hepatic duct & $1.54 \pm 0.63$ & 0.77 & $1.77 \pm 0.47$ & 0.83 & $<0.01$ \\
\hline $\begin{array}{l}\text { intrahepatic } \\
\text { ducts }\end{array}$ & $1.41 \pm 0.67$ & 0.81 & $1.67 \pm 0.53$ & 0.83 & $<0.01$ \\
\hline $\begin{array}{l}\text { proximal } \\
\text { pancreatic duct }\end{array}$ & $1.29 \pm 0.74$ & 0.82 & $1.50 \pm 0.64$ & 0.84 & $<0.01$ \\
\hline $\begin{array}{l}\text { distal pancreatic } \\
\text { duct }\end{array}$ & $1.14 \pm 0.81$ & 0.77 & $1.42 \pm 0.69$ & 0.83 & $<0.01$ \\
\hline average & $1.46 \pm 0.70$ & & $1.68 \pm 0.56$ & & \\
\hline
\end{tabular}

Level of diagnostic confidence for choledocholithiasis with 3D-TSE MRCP and 3DSPACE MRCP as average rating of all three readers. Confidence levels were identified for 10 segments of the pancreatobiliary tree (right column). A five-point scale was used $(-2$ = reliably no concrement; $-1=$ most likely no concrement; $0=$ not evaluable; $1=$ most likely concrement; 2 = reliably recognized concrement) and the modulus was used for further statistics. $\mathrm{k}$-values between the three reviewers are specified. Corresponding $\mathrm{p}$-values for the average segment rating for 3D-SPACE MRCP vs. 3D-TSE MRCP are given.

Die diagnostische Sicherheit wurde auf einer fünfstufigen Skala angegeben ( -2 = sicher kein Konkrement; -1 wahrscheinlich kein Konkrement; 0 nicht entscheidbar; 1 Konkrement wahrscheinlich; 2 Konkrement sicher), für weitere statistische Analysen wurde der Modulus verwendet. Gezeigt wird jeweils der Mittelwert für alle drei Untersucher. Die Interobserver-Reliabilität ( $\mathrm{k}$-Werte) der drei Untersucher wurden angegeben, sowie entsprechende p-Werte des Durchschnitts der 3D-SPACE-MRCP gegenüber der 3D-TSE MRCP.

whole hepatobiliary tree also in the clinical routine. This was especially true for the diagnostic confidence.

The superiority of 3D-SPACE was most evident in the imaging of small structures such as the cystic duct, distal common bile duct / papilla of Vater and pancreatic duct, which was related to better visibility of these structures mainly due to increased image sharpness. This is consistent with prior study results in healthy volunteers, where 3D-SPACE showed higher scores regarding duct visibility in all segments of the intrahepatic bile ducts [7]. Our results show that this advantage in depiction of small structures is also found under clinical conditions for patients referred to MRCP, and allows a higher diagnostic confidence especially in the periampullary region.

In addition, there was high interobserver agreement regarding the image quality and the diagnostic confidence, which indicates that a diagnostic assessment can be made also by radiologists with less experience in abdominal imaging, despite the fact that more experience leads to a slightly higher diagnostic confidence. In most clinical centers, 3D-TSE is still used with good results [10]. Our results confirm this practice, as all readers rated the image quality and diagnostic confidence for both $3 \mathrm{D}$ sequences very good. Our data suggest that by using the 3D-SPACE sequence, these results can be further improved. We found superiority of 3D-SPACE especially in the periampullary region (CBD, PV, DPD), which is usually the most difficult region to evaluate in MRCP studies [11]. Thus, the periampullary region can be better evaluated particularly in difficult patients with diagnostic results. In addition to our actual results, we are sure that upcoming technical advances will lead to an even higher spatial resolution and shorter acquisition times while giving diagnostic confidence levels that are the same as or better than the ones we found with the 3D-SPACE sequence.

\section{Conclusion}

Our study confirms that optimized 3D-SPACE MRCP is superior to conventional 3D-TSE MRCP regarding the image quality and the level of diagnostic confidence for choledocholithiasis. Because of the significantly better imaging results, we recommend replacing the conventional 3D-TSE sequence with an optimized 3D-SPACE sequence within a standard MRCP protocol.

\section{References}

1 Taylor AC, Little AF, Hennessy OF et al. Prospective assessment of magnetic resonance cholangiopancreatography for noninvasive imaging of the biliary tree. Gastrointestinal endoscopy 2002; 55: 17-22

2 Soto JA, Barish MA, Alvarez 0 et al. Detection of choledocholithiasis with MR cholangiography: comparison of three-dimensional fast spin-echo and single- and multisection half-Fourier rapid acquisition with relaxation enhancement sequences. Radiology 2000; 215: 737 745

3 Reinhold C, Guibaud L, Genin G et al. MR cholangiopancreatography: comparison between two-dimensional fast spin-echo and three-dimensional gradient-echo pulse sequences. Journal of magnetic resonance imaging: JMRI 1995; 5: $379-384$

4 Yamashita $Y$, Abe $Y$, Tang $Y$ et al. In vitro and clinical studies of image acquisition in breath-hold MR cholangiopancreatography: single-shot projection technique versus multislice technique. Am J Roentgenol American journal of roentgenology 1997; 168: 1449-1454

5 Asbach $P$, Klessen C, Kroencke TJ et al. Magnetic resonance cholangiopancreatography using a free-breathing T2-weighted turbo spin-echo sequence with navigator-triggered prospective acquisition correction. Magnetic resonance imaging 2005; 23: 939-945

6 Haystead CM, Dale BM, Merkle EM. N/2 ghosting artifacts: elimination at 3.0-T MR cholangiography with SPACE pulse sequence. Radiology 2008; 246: 589-595

7 Arizono S, Isoda H, Maetani YS et al. High-spatial-resolution three-dimensional MR cholangiography using a high-sampling-efficiency technique (SPACE) at 3T: comparison with the conventional constant flip angle sequence in healthy volunteers. Journal of magnetic resonance imaging: JMRI 2008; 28: 685-690

8 Morita S, Ueno E, Masukawa A et al. Comparison of SPACE and 3D TSE MRCP at $1.5 \mathrm{~T}$ focusing on difference in echo spacing. Magnetic resonance in medical sciences: MRMS: an official journal of Japan Society of Magnetic Resonance in Medicine 2009; 8: 101-105

9 Nakaura T, Kidoh M, Maruyama $N$ et al. Usefulness of the SPACE pulse sequence at $1.5 \mathrm{~T}$ MR cholangiography: comparison of image quality and image acquisition time with conventional 3D-TSE sequence. Journal of magnetic resonance imaging: JMRI 2013; 38: 1014-1019

10 Griffin N, Charles-Edwards G, Grant LA. Magnetic resonance cholangiopancreatography: the $A B C$ of MRCP. Insights into imaging 2012; 3 : $11-21$

11 Irie $H$, Honda $H$, Kuroiwa $T$ et al. Pitfalls in MR cholangiopancreatographic interpretation. Radiographics: a review publication of the Radiological Society of North America, Inc 2001; 21: 23 - 37 